San Jose State University

SJSU ScholarWorks

Master's Theses

Master's Theses and Graduate Research

Summer 2017

\title{
Diet Induced Obesity Alters Muscle Spindle Afferent Function in Adult Mice
}

Lubayna Elahi

San Jose State University

Follow this and additional works at: https://scholarworks.sjsu.edu/etd_theses

\section{Recommended Citation}

Elahi, Lubayna, "Diet Induced Obesity Alters Muscle Spindle Afferent Function in Adult Mice" (2017). Master's Theses. 4844.

DOI: https://doi.org/10.31979/etd.5hc9-8tjn

https://scholarworks.sjsu.edu/etd_theses/4844

This Thesis is brought to you for free and open access by the Master's Theses and Graduate Research at SJSU ScholarWorks. It has been accepted for inclusion in Master's Theses by an authorized administrator of SJSU ScholarWorks. For more information, please contact scholarworks@sjsu.edu. 


\title{
DIET INDUCED OBESITY ALTERS MUSCLE SPINDLE AFFERENT FUNCTION IN ADULT MICE
}

\author{
A Thesis \\ Presented to \\ The Faculty of the Department of Biology \\ San José State University \\ In Partial Fulfilment \\ of the requirements for the Degree \\ Master of Science
}

by

Lubayna Elahi

August 2017 
(C) 2017

Lubayna Elahi

ALL RIGHTS RESERVED 
The Designated Thesis Committee Approves the Thesis Titled

\title{
DIET INDUCED OBESITY ALTERS MUSCLE SPINDLE AFFERENT FUNCTION IN ADULT MICE
}

\author{
by \\ Lubayna Elahi \\ APPROVED FOR THE DEPARTMENT OF BIOLOGY \\ SAN JOSÉ STATE UNIVERSITY
}

August 2017

$\begin{array}{ll}\text { Katherine Wilkinson, Ph.D. } & \text { Department of Biology } \\ \text { Michael Sneary, Ph.D. } & \text { Department of Biology } \\ \text { Rachael French, Ph.D. } & \text { Department of Biology }\end{array}$ 


\section{ABSTRACT \\ DIET INDUCED OBESITY ALTERS MUSCLE SPINDLE AFFERENT FUNCTION IN ADULT MICE}

by Lubayna Elahi

Individuals with obesity are more likely to fall and exhibit balance instability. The reason for this is likely multifactorial, but there is some evidence that sensory function is impaired during obesity. We tested the hypothesis that muscle proprioceptor function is compromised in a mouse model of diet induced obesity. We used an in vitro musclenerve preparation to record muscle spindle afferent responses to physiological stretch and sinusoidal vibration. We compared the responses of mice on a control diet $(10 \%$ kcal fat) with those eating a high fat diet ( $60 \% \mathrm{kcal}$ fat) alone or in combination with either aspirin $(120 \mathrm{mg} / \mathrm{kg} /$ day in drinking water) or rosiglitazone $(0.01 \%$ in chow) for 10 weeks. Following high fat diet feeding, adult mice exhibited decreased muscle spindle afferent responses to stretch and lower dynamic sensitivity. Treatment with aspirin or rosiglitazone did not completely rescue muscle spindle afferent responsiveness. Due to the importance of muscle spindle afferents to proprioception and motor control, decreased muscle spindle afferent responsiveness may contribute to balance instability during obesity. Future studies should test this hypothesis in the human population. 


\section{ACKNOWLEDGMENTS}

First, I would like to thank members of the Wilkinson lab who assisted with running experiments and analyzing data. I would like to thank Shreejit Padmanabhan for analyzing muscle tension data, and Adam Abtahie and Adam Cai for assisting with vibration data analysis and crosschecking of data analysis.

Second, I would like to thank Larry Young and Nelia Medeiros for providing essential animal training and continuous assistance with animal work.

Third, I would like to thank my thesis committee members Dr. Michael Sneary and Dr. Rachael French for providing valuable criticisms.

Finally, I would like to thank my amazing mentor Dr. Katherine Wilkinson for believing in me and giving me the opportunity to conduct research in her laboratory. Her encouragement and guidance helped me all throughout my research, writing of the thesis, and helped me become a better scientist. 


\section{TABLE OF CONTENTS}

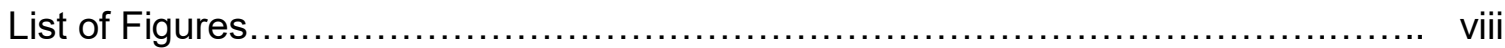

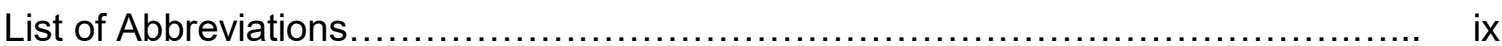

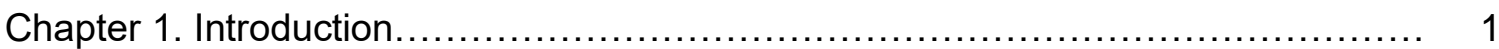

Chapter 2: Diet Induced Obesity Alters Muscle Spindle Afferent Function in Adult

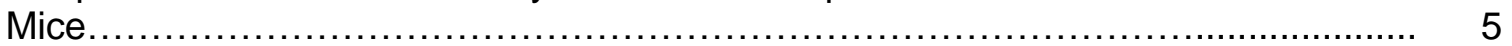

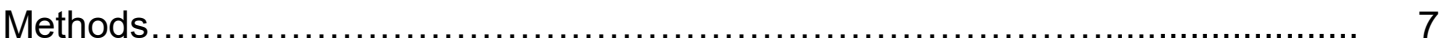

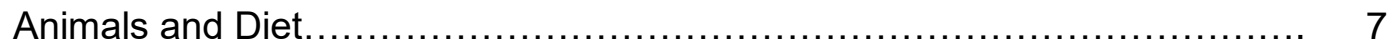

Electrophysiological Recording of Muscle Sensory Neuron................. 8

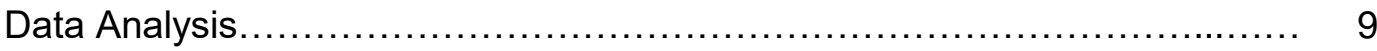

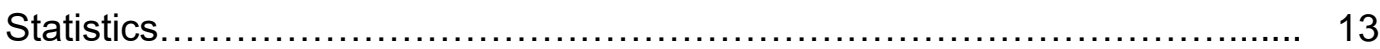

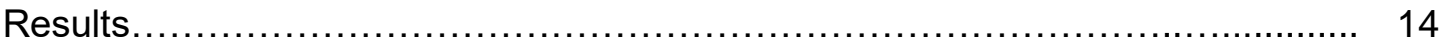

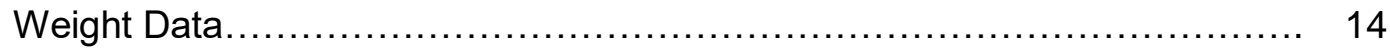

Muscle Spindle Afferent Response to Ramp and Hold Stretch and

Sinusoidal Vibration........................................................... 14

Muscle Spindle Afferent Response to Rosiglitazone and Aspirin............. 16

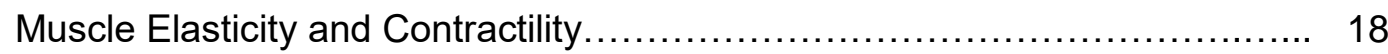

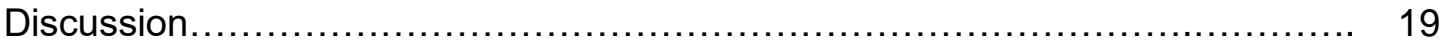

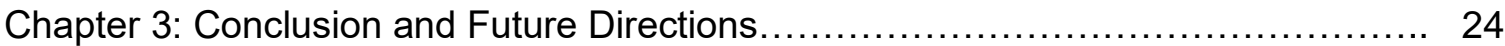

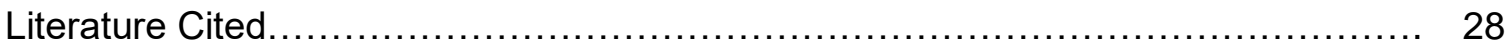




\section{LIST OF FIGURES}

Figure 1. Data analysis procedure ....................................................... 12

Figure 2. Final body weight following 10-week treatment period..

Figure 3. Mice fed a HFD exhibit impaired MSA

response to stretch and vibration.

Figure 4. Muscle elasticity following high fat feeding

no different than control. 


\section{LIST OF ABBREVIATIONS}

$\begin{array}{ll}\text { ASP } & \text { aspirin } \\ \mathrm{BL} & \text { baseline } \\ \mathrm{CaCl}_{2} & \text { calcium chloride } \\ \mathrm{CON} & \text { control } \\ \mathrm{CSA} & \text { cross sectional area } \\ \mathrm{DI} & \text { dynamic index } \\ \mathrm{DR} & \text { dynamic response } \\ \mathrm{EDL} & \text { the extensor digitorum longus } \\ \mathrm{EPE} & \text { parallel modulus of elasticity } \\ \mathrm{ESE} & \text { series modulus of elasticity } \\ \mathrm{HEPES} & \text { 10 N-2-hydroxyethylpiperazine- } N^{\prime} \text {-2-ethanesulfonic acid } \\ \mathrm{HFD} & \text { high fat } \\ \mathrm{IL} & \text { interleukin } \\ \mathrm{KCl} & \text { potassium chloride } \\ \mathrm{LO} & \text { optimal length } \\ \mathrm{MgSO}{ }_{4} & \text { magnesium sulphate } \\ \mathrm{MSA} & \text { muscle spindle afferent } \\ \mathrm{NaC}{ }_{6} \mathrm{H}_{11} \mathrm{O} & \text { sodium gluconate } \\ \mathrm{NaCl} & \text { sodium chloride } \\ \mathrm{NF}-\mathrm{KB} & \text { nuclear factor kappa-light-chain-enhancer of activated B cells } \\ \mathrm{RZG} & \text { rosiglitazone } \\ \mathrm{SR} & \text { static response }\end{array}$




\section{CHAPTER 1 \\ INTRODUCTION}

Obesity leads to an increase in body mass (Flegal et al. 2012), negatively alters body balance (Teasdale et al. 2013), decreases postural stability (Hue et al. 2007), and increases the risk of fall associated injuries (Finkelstein et al. 2007). In comparison to a healthy individual, a person with obesity is $31 \%$ more likely to have experienced a fall (Mitchell et al. 2014). Following a postural perturbation, individuals with obesity have a harder time regaining balance (Matrangola and Madigan 2011). Individuals with obesity also exhibit increased postural sway (Singh et al. 2009; Wu and Madigan 2014), gait abnormalities (Mcgraw et al. 2000; Colné et al. 2008), and a greater motor balance command variability when compared to their lean counterparts (Simoneau and Teasdale 2015). Children with obesity have been shown to have poor gross and fine motor skills implying impairment in sensory processing and integration (Gentier et al. 2013). Decreased sensory action potential amplitude and duration have been observed in nondiabetic people with obesity, suggesting an alteration in slow conducting fibers during obesity (Yadav et al. 2016). The exact mechanism by which obesity results in balance impairments is not clear; however, there is some evidence that impairments in the somatosensory system may be linked with the balance deficits seen in obesity.

Proprioception is the innate sense of relative body position and movement and is essential for balance control. Sensory signals from the proprioceptive, cutaneous, visual, and the vestibular systems are important for proprioception and enable a person to maintain proper balance. (Guskiewicz and Perrin 1996; Shaffer and Harrison 2007). There is evidence for impairment to sensory function necessary for proprioception in obesity. Men with obesity have been reported to have poor proprioceptive feedback 
when presented with discriminatory tasks (Gardner, Salaz, Reyes, \& Brake, 1983). Boys with obesity exhibit impairments in proprioceptive function in knee joints (Wang et al. 2008). Plantar mechanoreceptors sense foot pressure and play a role in equilibrium control (Watanabe and Okubo 1981) and the regulation of compensatory stepping reactions (Perry et al. 2000). Individuals with obesity have impaired plantar receptor sensitivity. The impairment of plantar mechanoreceptors has been hypothesized to be either due to the increased mechanical demand due to the larger body mass or due to continuous pressure from supporting the larger mass leading to hyperactivation of plantar mechanoreceptors (Dutil et al. 2012). Taken together, this evidence suggests decreased somatosensory function and integration during obesity.

Muscle spindle afferents are the most important proprioceptive afferents (Proske and Gandevia 2012). Muscle spindles are specialized mechanoreceptors found in skeletal muscles. The muscle spindle complex is made up of dynamic intrafusal fibers known as the nuclear bag1 fibers, static bag2 fibers, and nuclear chain fibers. Primary afferent endings (Group la) innervate these intrafusal fibers at the central equatorial region, and secondary afferents are located within the juxtaequatorial region of the nuclear chain fibers (Cameron-Tucker, 1983). The muscle spindle afferents relay information to the central nervous system about changes in velocity and muscle length due to stretch and movement (Fritz-Ritson 1982). Changes in muscle spindle afferent anatomical and physiological properties have been observed in pathological conditions such as diabetes (Muller et al. 2008a) and aging (Rosant et al. 2007). Since muscle spindle afferents play a predominant role in proprioception and motor control, in this study we tested the hypothesis that muscle spindle afferent function is altered in a mouse model of high fat diet induced obesity in both male and female adult mice. 
Female mice are protected from metabolic changes associated with high fat diet induced obesity (Pettersson et al. 2012). Ovarian hormones are thought to play an important role in protecting female mice both against high fat diet induced weight gain (Hong et al. 2009) and low grade systemic inflammation due to obesity (Pettersson et al. 2012). In addition, female mice are also protected against high fat diet induced remodeling of skeletal muscle fiber properties (Denies et al. 2014). Therefore, we tested the hypothesis that there is a sex difference in the response of muscle spindle firing due to obesity.

During obesity, many inflammatory cytokines such as TNF- $\alpha$, IL-6, and IL-1ß are markedly heightened in obese tissues (Gregor and Hotamisligil, 2011). Therefore, we also tested if blocking some of the other obesity related changes in the presence of weight gain could rescue MSA deficits. To test this, we determined whether two drugs with anti-inflammatory actions, aspirin and rosiglitazone, could rescue impaired muscle spindle afferent function following high fat feeding. Rosiglitazone is a peroxisome proliferator-activated gamma agonist that is an insulin sensitizer (Tiikkainen et al. 2004) and also has anti-inflammatory properties. When fed in combination with a high fat diet, rosiglitazone downregulates cytokines such as IL-6 and NF-KB. Rosiglitazone reduces kidney inflammation (Wang et al., 2011) and prevents severe pancreatic inflammation by suppressing IL-6, IL-12+ and IL-18 levels (Pini et al., 2012). Aspirin is a non-steroidal anti-inflammatory drug that functions by inhibiting cyclooxygenase, an enzyme that is necessary for synthesizing prostaglandins (Diepen et al., 2011; Kendig et al., 2008; Pascucci, 2002). In combination with a high fat diet, aspirin reduces metabolic syndrome induced inflammation by suppressing NF-kB activity and by improving plasma triglyceride levels (van Diepen et al., 2011 and Hundal et al., 2002). When administered 
with a high fat diet, both Rosiglitazone and aspirin decrease inflammation even though the animals gain as much weight as animals given a high fat diet alone (van Diepen et al. 2011; Pini et al. 2012)

The results of this study will determine whether muscle spindle afferent dysfunction could contribute to proprioceptive dysfunction during obesity in adult male and female mice. If so, this would suggest a potential causal mechanism for the impaired balance control observed during obesity. 


\section{CHAPTER 2}

\section{DIET INDUCED OBESITY ALTERS MUSCLE SPINDLE AFFERENT FUNCTION IN ADULT MICE}

Individuals with obesity are more likely to fall (Finkelstein et al. 2007; Fjeldstad et al. 2008; Madigan et al. 2014), more likely to visit the hospital with fall related injuries (Matter et al. 2007), and have a higher risk of disability from falls than normal weight individuals (Himes and Reynolds 2012). Individuals with obesity also exhibit increased sway during standing and altered gait (Hue et al. 2007; Ko et al. 2010; McGraw et al. 2000; Menegoni et al. 2009), which are risk factors for falling (Ganz et al. 2007) and suggestive of proprioceptive deficits. The reason for impaired balance in obesity is not completely understood, although the increase and change in center of mass during obesity is important (Corbeil et al. 2001; Costello et al. 2012; Handrigan et al. 2012). However, there is evidence for sensory deficits in obesity that could also contribute to impaired balance. There is larger variability in balance motor commands in people with obesity that could be due to less reliable sensory information and/or increased reliance on the more variable input from the visual and vestibular systems (Simoneau and Teasdale 2015). People with obesity also exhibit a decreased ability to use somatosensory input to maintain balance (Cheung and Azevedo 2015), a decreased ability to discriminate between object weights (Gardner et al. 1983), and require more attentional skills to maintain posture in difficult postural conditions (Mignardot et al. 2010). Decreased fine motor skills are also observed in children with obesity even when sitting (D'Hondt et al. 2008). These findings suggest that obesity may alter the central processing and/or function of somatosensory afferents, but few studies have directly tested this hypothesis. 
A better understanding of how obesity affects somatosensory afferents is needed due to their importance in motor control and the maintenance of balance. The sensitivity of the plantar mechanoreceptors is decreased in people with obesity (D'Hondt et al. 2011; da Rocha et al. 2014; Wu and Madigan 2014). These cutaneous mechanoreceptors provide information about foot pressure and placement and are important for balance control (Billot et al. 2013). The primary proprioceptive afferents are the Group la and II sensory neurons that innervate the muscle spindle (Proske and Gandevia 2012) and the effect of obesity on muscle spindle afferents is unknown. Muscle spindle afferents convey information about muscle length and limb position to the central nervous system which is then used to develop a three dimensional representation of body position in space (Matthews 1981; Proske and Gandevia 2012). In addition, the Group la muscle spindle afferents also comprise the sensory component of the monosynaptic muscle stretch reflex, which is critical for fast error correction during ongoing movement (Proske and Gandevia 2012). Impairment in muscle spindle afferent structure and function is observed in other conditions accompanied by poor balance and an increased risk of falling, including aging and diabetes (Kim et al. 2007; Miwa et al. 1995; Muller et al. 2008; Rosant et al. 2007; van Deursen et al. 1998).

In this study, we tested the hypothesis that muscle spindle afferent function is altered in a mouse model of diet induced obesity. We chose a mouse model since direct measurement of sensory afferent response properties in humans is difficult, as is properly controlling for all co-morbidities, including diabetic neuropathy, in populations with obesity. High fat feeding in mice reduces motor coordination in the rotorod test and decreases voluntary locomotor speed, similarly to the decreased gait speed observed in humans (Griffin et al. 2010). We used an in vitro muscle-nerve preparation to measure 
muscle spindle afferent responses to physiological stretch and vibration in adult mice of both sexes (Wilkinson et al. 2012). We also determined whether there was a sex difference in the muscle spindle afferent response to diet induced obesity since there is a sex difference in the development and adverse effects of obesity in mice. Male mice are known to exhibit greater (Hong et al. 2009) and faster weight gain (Yang et al. 2014) than female mice when fed a high fat diet. Female mice are also protected from increases in adipose tissue inflammation, glucose intolerance, and other metabolic effects (Pettersson et al. 2012). Obesity also leads to metabolic changes, chronic inflammation (Gregor and Hotamisligil 2011), alterations in sympathetic nervous system tone (Davy and Orr 2009), and other factors that could potentially alter the signaling of sensory afferents. We tested the additional hypothesis that factors other than weight gain alone could mediate the observed decreases in muscle spindle afferent function. In male mice, where the largest deficits in muscle spindle afferent signaling were observed, we administered one of two drugs in addition to the high fat diet: aspirin, a non-steroidal anti-inflammatory drug which also improves glucose tolerance (Kendig et al. 2008), or rosiglitazone, a drug that normalizes insulin sensitivity and sympathetic nervous system signaling in addition to having anti-inflammatory effects (Berger and Moller 2002; Yosefy et al. 2004).

\section{METHODS}

\section{Animals and Diets}

All of the procedures were approved and authorized by the Institutional Animal Care and Use Committee at San José State University. Sixty C57BL/6 4-5 wk old mice (22 M, $22 \mathrm{~F}$ ) were purchased from Simonsen Laboratories (Gilroy, CA) and housed in cages of 5-8 mice under a 12:12 hour light-dark cycle. All mice were fed the control diet (10\% kcal 
fat; D12450J Research Diets; New Brunswick, NJ) and regular drinking water (pH 6.4) for a period of 1 week to acclimatize them to the texture of the special diet. After 1 week the mice were assigned to one of 2 experimental conditions for the following 10 weeks. The control group (CON) remained on the control diet $(\mathrm{n}=10 \mathrm{M}$ and $11 \mathrm{~F})$ and the high fat diet group (HFD, $n=12 \mathrm{M}$ and $11 \mathrm{~F})$ was fed a high fat diet $(60 \% \mathrm{kcal}$ fat; Research Diets D12492). Rosiglitazone group (RZG, $n=9 M$ ) was given the HFD containing $0.01 \%$ Rosiglitazone (LKT Laboratories, Inc.; St Paul, MN; (Pini et al. 2012)). The aspirin group (ASP, $n=7 M$ ) was fed the HFD and given aspirin in their drinking water $(120 \mathrm{mg} / \mathrm{kg} /$ day; pH 6.4; Sigma Aldrich; St. Louis, MO; (van Diepen et al. 2011)). Animals were weighed once a week for the duration of the study.

\section{Electrophysiological Recording of Muscle Sensory Neuron Activity}

Direct recording of muscle sensory neuron function was performed using an isolated muscle-nerve preparation (detailed methods can be found in (Franco et al. 2014;

Wilkinson et al. 2012)). On the day of the experiment, mice were placed in an induction chamber, deeply anesthetized with isoflurane (5\%), decapitated, and skinned. The legs were removed and placed into an oxygenated $\left(95 \% \mathrm{O}_{2} / 5 \% \mathrm{CO}_{2}\right)$ dish filled with low calcium, high magnesium artificial cerebrospinal fluid, containing in mM: $128 \mathrm{NaCl}, 1.9$ $\mathrm{KCl}, 1.2 \mathrm{KH}_{2} \mathrm{PO}_{4}, 26 \mathrm{NaHCO}_{3}, 0.85 \mathrm{CaCl}_{2}, 6.5 \mathrm{MgSO}_{4}$, and 10 glucose ( $\mathrm{pH}$ of 7.4). The extensor digitorum longus (EDL) muscle and the deep peroneal branch of the sciatic nerve were dissected and placed in an oxygenated $\left(100 \% \mathrm{O}_{2}\right)$ tissue bath of synthetic interstitial fluid containing in $\mathrm{mM} 123 \mathrm{NaCl}, 3.5 \mathrm{KCl}, 0.7 \mathrm{MgSO}_{4}, 1.7 \mathrm{NaH}_{2} \mathrm{PO}_{4}, 2.0$ $\mathrm{CaCl}_{2}, 9.5 \mathrm{NaC}_{6} \mathrm{H}_{11} \mathrm{O}$ (sodium gluconate), 5.5 glucose, 7.5 sucrose, and $10 \mathrm{~N}-2$ hydroxyethylpiperazine- $N$ '-2-ethanesulfonic acid (HEPES) (pH 7.4 0.05 ; (Koltzenburg et al. 1997)). Both tendons were sutured with 5-0 nylon thread, with one end tied to a fixed 
post and the other end tied to the lever arm of a dual force and length controller and transducer (300C-LR, Aurora Scientific, Inc.; Aurora, ON, Canada). All experiments were conducted at $24^{\circ} \mathrm{C}$.

The length at which the muscle produced the maximal twitch contractile force, or optimal length $\left(L_{\circ}\right)$, was determined following stimulation via bath electrodes $(0.5 \mathrm{~ms}$ pulse width, supramaximal voltage; S88 Stimulator, Grass Technologies; San Carlos, CA). The cut end of the nerve was suctioned into a bipolar glass electrode and connected to an extracellular amplifier with headstage (Model 1800, A-M Systems; Sequim, WA). Neural responses to a battery of ramp and hold stretches and sinusoidal vibrations were then digitized and recorded (PowerLab, ADInstruments; Sydney, Australia). The muscle was stretched to three physiological lengths $(2.5 \%, 5 \%$, and $7.5 \%$ of $L_{o} ; 40 \% L_{o} / s$ ramp speed). Each stretch was repeated three times with a 1 min rest period in between to prevent muscle thixotropic effects. Sinusoidal vibrations $9 \mathrm{~s}$ in length were performed at 4 frequencies $(10,25,50$, and $100 \mathrm{~Hz})$ and 4 amplitudes (5, 25,50 and $100 \mu \mathrm{m}$ ) with $1 \mathrm{~min}$ rest in between, for a total of 16 different vibrations. At the end of the experiment, the muscle was contracted 60 times at $1 \mathrm{~Hz}$ frequency $(0.5$ $\mathrm{ms}$ pulse width). The maximal tetanic contractile force was then measured (500 ms train, $120 \mathrm{~Hz}, 0.5 \mathrm{~ms}$ pulse width). Wet weight of the EDL was determined and cross sectional area (CSA) calculated as (mass)/(L $\mathrm{x}$ density), using $1.06 \mathrm{~kg} / \mathrm{L}$ for muscle density (Brooks and Faulkner 1988).

\section{Data Analysis}

The Spike Histogram function of Lab Chart (ADInstruments) was used to identify individual afferents based on spike shape. Individual muscle spindle afferents were identified functionally by determining if they increased firing frequency to stretch and 
paused during the 60 twitch contractions (Hunt and Kuffler 1951). A total of 115 muscle spindle afferents were used in this study (17 M CON, 21 M HFD, 20 F CON, 20 F HFD, $18 \mathrm{M}$ RZG, $19 \mathrm{M} \mathrm{ASP}$ ). Due to technical reasons, responses to both stretch and vibration were not recorded for all afferents. Instantaneous firing frequency was measured at baseline $(\mathrm{BL})$, at the beginning of stretch $(0.5 \mathrm{~s}$ after ramp completed, dynamic response or DR), and during the plateau phase of stretch ( $0.5 \mathrm{~s}$ before end of stretch, static response or SR; Fig 1A\&B). Values were averaged for the 3 repeats of each stretch as no systematic order effect was observed. Dynamic Index (DI) was calculated as DR-SR. For each vibration we determined if the afferent could entrain by firing at the same time during each cycle of vibration (Fig 1E). We confirmed that all afferents with baseline firing frequency $(B L)$ paused in response to twitch contraction, with the exception of 13 afferents that could not be analyzed due to technical issues. Because all included afferents displayed the characteristic adaptation of firing frequency during the hold phase of stretch typical of muscle spindle afferents (Fig 1B), we are reasonably confident that only muscle spindle afferents were included in our sample. 
Maximal tetanic contraction strength normalized to muscle CSA was determined for each muscle. Muscle tension at baseline, peak tension during stretch, and plateau tension immediately before stretch was released were determined at the $5 \% \mathrm{~L}_{0}$ stretch length (Fig 1D). We calculated the parallel ( $E_{P E}$ and series modulus of elasticity ( $\left.E_{S E}\right)$ normalized to muscle CSA using the following formula from Wolff et al. 2006):

$$
E=\frac{\frac{\Delta F}{C S A}}{\frac{\Delta L}{L_{o}}}
$$

Equation 1: Modulus of elasticity. $\Delta F$ is the difference in tension $(\mathrm{mN})$ from baseline; $\Delta L$ is the change in length $(\mathrm{mm})$ from $\mathrm{L}_{\mathrm{o}} . \Delta F$ measured from baseline to peak of stretch for $\mathrm{E}_{\mathrm{SE}}$ and baseline to end of stretch for $\mathrm{E}_{\mathrm{PE}}$ 


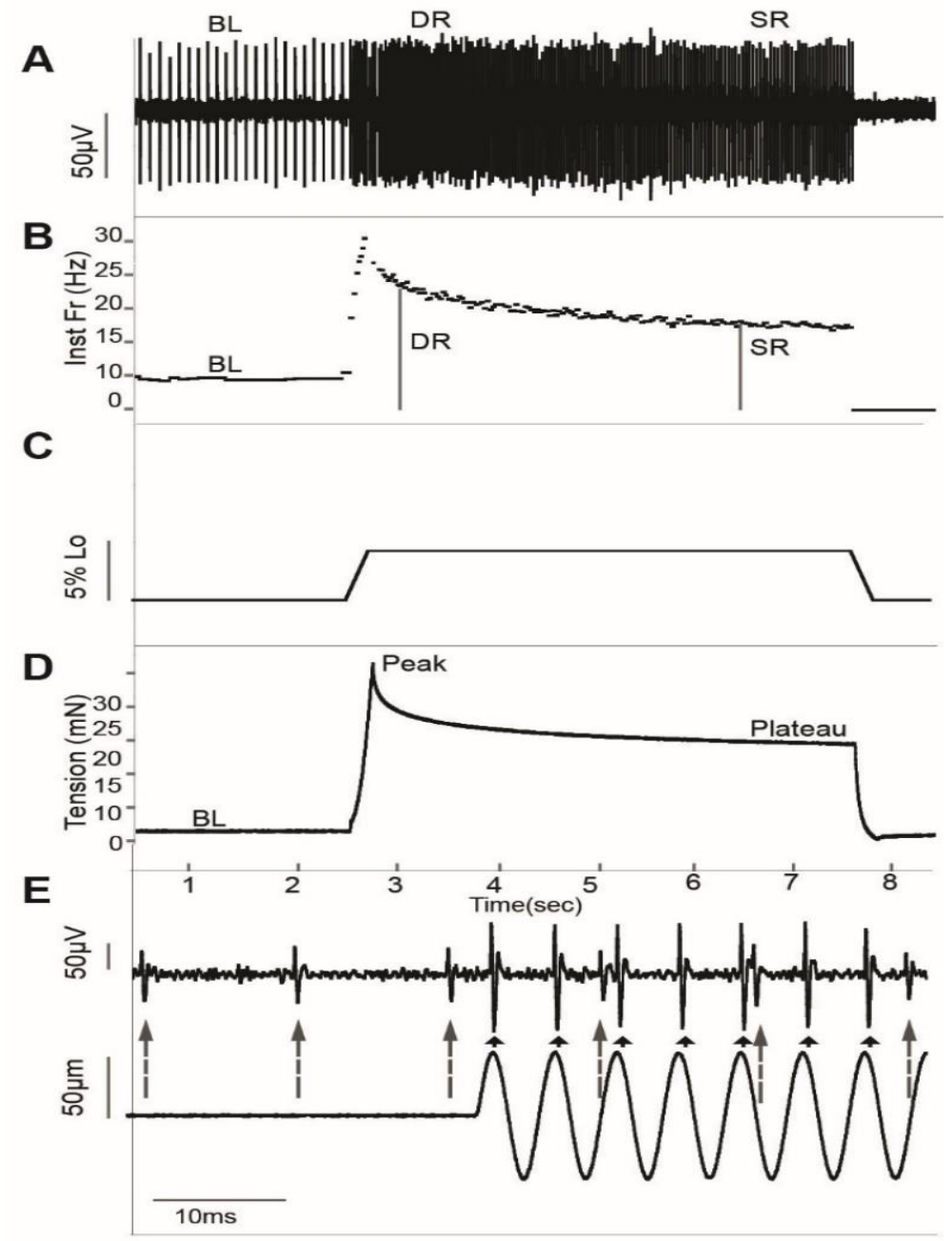

Figure 1: Data analysis procedure. (A) Raw trace of muscle spindle afferent response to ramp and hold stretch. Time where baseline (BL), dynamic response (DR), and static response (SR) firing frequency calculated are shown on the trace. (B) Instantaneous frequency (inst fr; $\mathrm{Hz}$ ) response to ramp and hold stretch of identified unit during stretch. Time BL, DR and SR calculated identified on graph. (C) Length change during stretch. (D) Muscle tension during stretch. Time where baseline tension (BL), maximum tension (peak), and end of ramp tension (plateau) were measured indicated on trace. (E) Raw trace of neural response (top) to sinusoidal vibration (length change bottom). The larger unit exhibits 1:1 entrainment as denoted by small black arrows. The smaller unit's firing rate is unaffected by vibration as denoted by large gray arrows. 


\section{Statistics}

Body weights on the day of experiment were compared to the CON group of the same sex using independent samples t-tests for females and a one factor ANOVA model with Dunnett's post-hoc for the 4 male groups. EPE, and ESE in the six treatment groups (F CON, F HFD, M CON, M HFD, M ASP, M RSZ) were compared using a one factor ANOVA model with planned comparisons to compare F CON to F HFD, M CON to M HFD, M CON to M ASP, M CON to M RSZ and the difference of F HFD and F CON to the difference of M HFD and M CON. P-values were adjusted for multiple comparisons using the Hochberg procedure. The proportion of afferents without baseline firing was compared with a z-test. Group BL, DR, SR, and DI were compared using a three factor ANOVA model, with stretch length, sex, and experimental condition (CON and HFD). Since only male mice were given the drug treatments, we fit a separate two factor ANOVA model for male mice (stretch length and condition) in all 4 treatment groups (CON, HFD, ASP, RSZ) with Dunnett's post-hoc test against M CON. Muscle weight, $\mathrm{L}_{\circ}$, CSA, and maximal tetanic contraction strength were compared with a two factor ANOVA model (sex and condition). Ability to entrain to vibration was fitted as a function of vibration amplitude, vibration frequency, sex, and condition (CON and HFD) using a logistic regression model. Male mice in all 4 treatment groups were compared with a separate logistic regression model (amplitude, frequency, condition) and different condition groups were compared to M CON using simple contrasts. Values are given as mean \pm standard deviation, error bars on graphs indicate $95 \%$ confidence intervals, and all differences are considered significant if $p<0.05$. 


\section{RESULTS}

Weight gain

Both male and female mice on a HFD gained more weight than their respective control groups by the end of 10 weeks (both $\mathrm{M}$ and $\mathrm{F}, \mathrm{p}<0.05$; Fig 2). Male mice given a HFD plus RSZ gained significantly more weight than M CON $(p<0.05)$; however, male mice given a HFD plus ASP did not ( $p=0.08$; Fig 2).

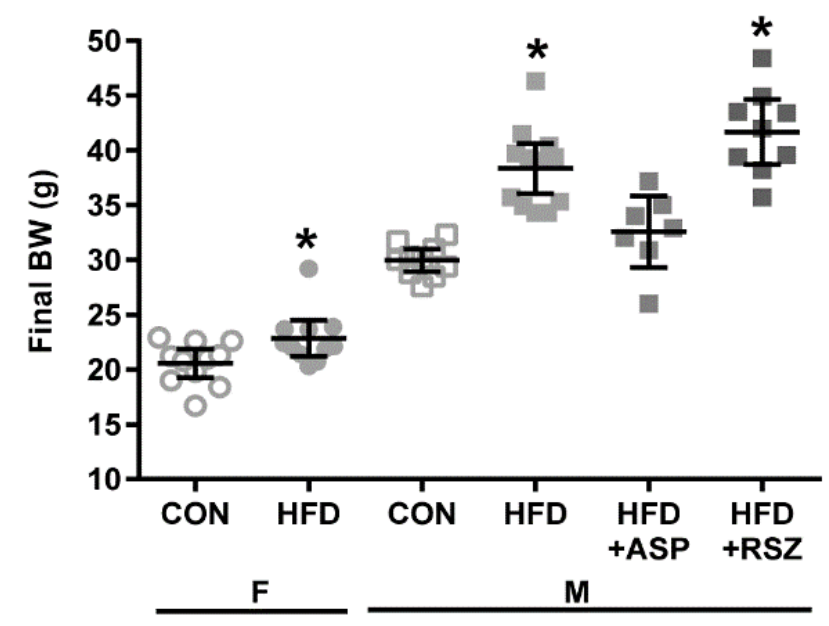

Figure 2: Final body weight following 10-week treatment period. Individual animal weights (circles for female $(F)$, squares for male $(M)$ ) as well as group means and $95 \%$ confidence interval shown. * $p<0.05$ versus same sex $C O N$; independent samples t-test for F; one-factor ANOVA with Dunnett's post-hoc for M.

Muscle Spindle Afferent Response to Ramp and Hold Stretch and Sinusoidal Vibration Altered by High Fat Diet

We first tested the hypothesis that 10 weeks on a HFD would alter muscle spindle afferent static sensitivity in both male and female mice. We compared muscle spindle afferent firing rates at BL, $0.5 \mathrm{~s}$ into stretch (DR), and $3.5 \mathrm{~s}$ into stretch (SR). Overall, mice fed a HFD were less likely to have a non-zero baseline firing rate $(71 \% \mathrm{CON}$ vs 54\% HFD; $p<0.05)$; however, there was a sex difference in this response. In male mice, 
significantly more CON afferents had a non-zero baseline firing rate $(88 \% \mathrm{M}$ CON vs. $52 \%$ M HFD; $p<0.05)$ and this proportion was similar to that observed in previous studies (Wilkinson et al. 2012). In females, fewer CON afferents had BL firing than in the male CON group, but there was no difference in the percentage of afferents with baseline firing between conditions ( $53 \%$ F CON vs. 56\% F HFD; $p=0.87$ ). Average BL firing rates of afferents with non-zero firing rates were significantly lower in female mice than male mice (F BL: $9.0 \pm 4.4 \mathrm{~Hz}$ vs. M BL: $12.5 \pm 5.4 \mathrm{~Hz}$; sex main effect $p<0.05$ ), but $B L$ firing rate was not significantly different with HFD (condition main effect $p=0.26$; sex * condition $\mathrm{p}=0.63)$. Both male and female CON and HFD mice showed linear increases in firing rate at both the beginning (DR) and end (SR) of stretch in response to increasing stretch length as expected (stretch length main effect $p<0.05$ for $D R$ and $S R$ ). DR and SR were significantly lower in HFD mice than CON mice (condition main effect $p<0.05$ for DR and SR), with both M and F mice exhibiting the same pattern (sex * condition $p=0.57$ for $S R$ and $p=0.84$ for $D R$ ). There was also a sex difference, with female mice having lower DR and SR firing rates than male mice (sex main effect $p<0.05$ for $D R$ and SR; Fig 3 A\&B). Overall, static sensitivity of muscle spindle afferents following HFD was lower in both male and female mice.

We next tested the hypothesis that muscle spindle afferent dynamic sensitivity was altered by HFD in mice of both sexes by measuring DI and ability to entrain to vibration. DI, or the 2-point slope $0.5-3.5$ s of stretch, was significantly greater with increasing stretch length as expected (stretch length main effect $p<0.05$ ). DI was significantly lower in HFD animals (condition main effect $\mathrm{p}<0.05$ ). There was no sex difference in DI (main effect sex $p=0.78$; sex ${ }^{*}$ condition $p=0.49$ ). As expected, afferents were less able to entrain to low amplitude and high frequency vibrations (main effect of amplitude \& 
vibration $\mathrm{p}<0.05)$. On average, HFD afferents were less able to entrain to vibration, especially low amplitude vibration, than CON afferents, suggesting decreased dynamic sensitivity in obese mice (main effect of condition $\mathrm{p}<0.05$; Fig $3 \mathrm{E}-\mathrm{H}$ ). However, there was a sex difference as well (main effect of $\operatorname{sex} p<0.05$ ) and when $F$ mice alone were analyzed there was no significant effect of HFD (condition $p=0.71$ ). Overall, dynamic sensitivity was reduced following a HFD, although the effects were weaker in female mice.

Muscle Spindle Afferent Deficits in Response to High Fat Diet Not Completely Rescued by Rosiglitazone or Aspirin

Finally, we tested the hypothesis that treatment with RSZ or ASP during high fat feeding could rescue muscle spindle afferent sensitivity in male mice. Male mice were chosen as they exhibited the greatest deficits following HFD. The RSZ but not ASP animals were less likely to have baseline firing than CON (35\% RSZ; 79\% ASP; 88\% CON). DR and SR were still significantly lower in both drug groups (main effect of condition and stretch length $p<0.05$; Fig $3 C \& D$ ), suggesting no improvement of spindle afferent static responsiveness with drug treatment. There was a main effect of condition on DI; however, only HFD and ASP groups had a significantly lower DI than CON (Dunnett's $p<0.05$ for HFD and ASP; RSZ $p=0.31$ ). All afferents were less likely to entrain to high frequency and low amplitude vibrations (main effects of frequency and vibration) as expected. Afferents from male HFD and ASP groups were less able to entrain to vibration than M CON afferents (main effect of condition p,0.05; Dunnett's $\mathrm{p}<0.05$ for HFD and ASP; Fig $3 \mathrm{H} \& \mathrm{~J})$. The ability of RSZ animals to entrain to vibration was no different than CON, suggesting an improvement in dynamic sensitivity with RSZ 
treatment (Dunnett's $p=0.13$; Fig 3I). In summary, static sensitivity was unaffected by either drug treatment but RSZ did improve both measures of dynamic sensitivity.
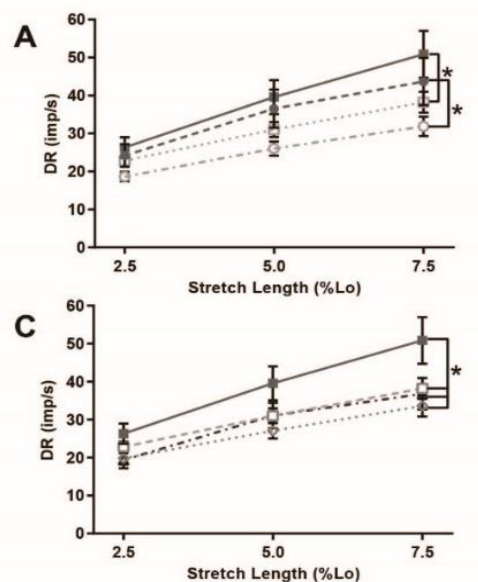

E
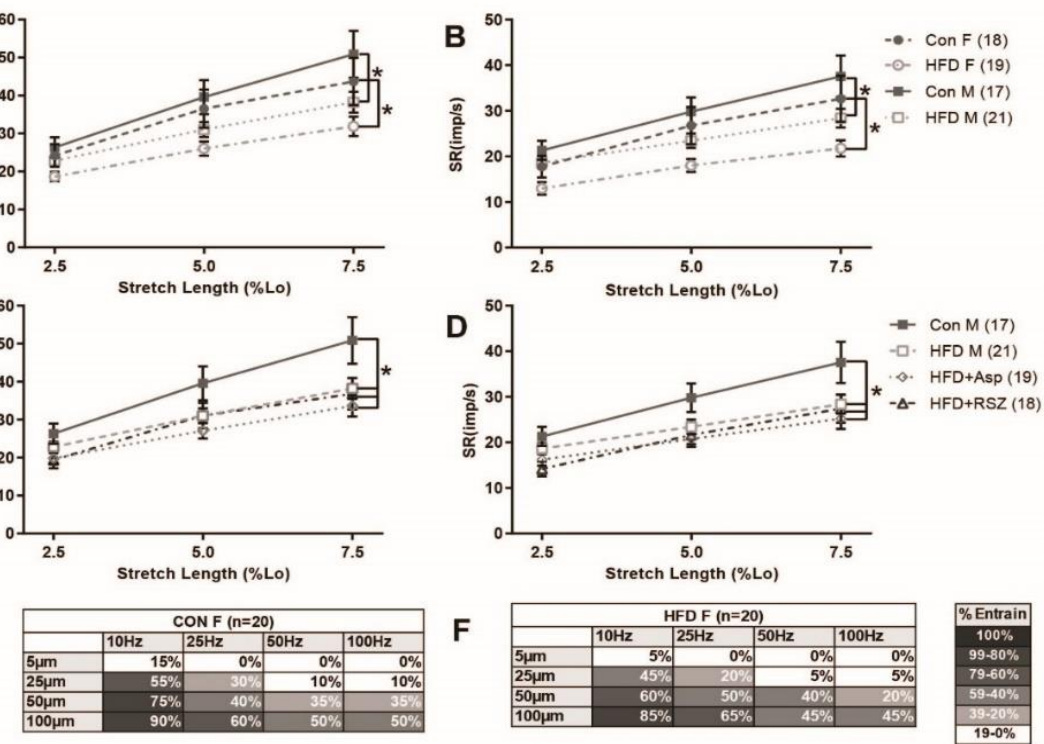

$\mathbf{F}$
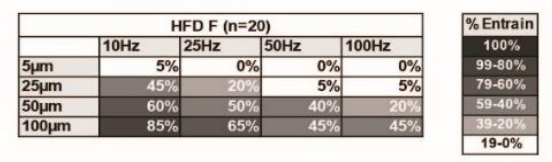

G

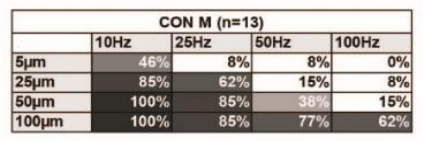

H

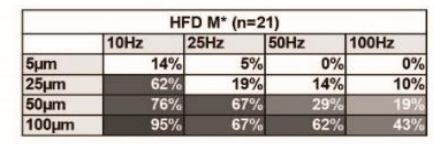

I

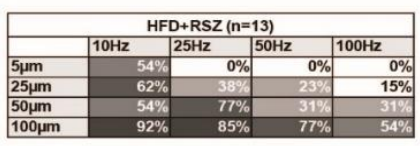

$\mathbf{J}$

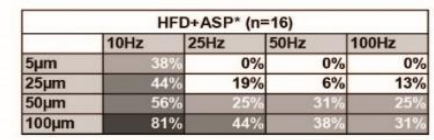

Figure 3: Mice fed a HFD exhibit impaired MSA response to stretch and vibration. Comparing only HFD to CON groups, dynamic response (DR; A) and static response (SR; B) significantly decreased in both M and F mice fed a HFD. F CON mice had significantly lower DR and SR responses than $\mathrm{M}$ mice. Comparing only $\mathrm{M}$ mice, mice fed either HFD+RSZ or HFD+ASP also exhibited significantly decreased DR (C) and SR (D) compared to M CON. Error bars denote \pm SEM; * denotes $p<0.05$ from CON of same sex using three factor ANOVA (stretch length, condition, sex; A-B) or two factor (stretch length \& condition; C-D) ANOVA plus Dunnett's post hoc from M CON. Tables E-J denote percentage of afferents that can entrain to each of the 16 vibrations. Vibration amplitude increases from top to bottom and frequency increases left to right. Darker shades denote a greater percentage of entrained units. No difference in ability to entrain to vibration was observed between CON and HFD female mice when analyzed separately using a logistic regression model (amplitude, frequency, condition; E \& F). Afferents from male mice fed a HFD (H) or HFD+ASP (J) less likely to entrain to vibration than $M$ CON afferents $(G)$. No difference in entrainment was observed between mice fed HFD+RSZ (I) and M CON afferents (G). Logistic regression model (amplitude, frequency, condition) followed by user defined contrasts; ${ }^{*}<<0.05$ from M CON. 
Muscle Elasticity and Contractility Unchanged by High Fat Diet

EDL muscle wet weight, CSA, and $\mathrm{L}_{0}$ were not altered by HFD or either drug treatment (main effect of condition $p=0.99,0.88,0.11$ respectively). As expected due to the lower female body weights, EDL muscle weight and $L_{0}$ were significantly lower in female mice (main effect of sex $p<0.05$; muscle weight $F: 9.5 \pm 1.5 \mathrm{mg}, \mathrm{M}: 11.2 \pm 1.5$ $\left.\mathrm{mg} ; \mathrm{L}_{\circ} \mathrm{F}: 11.0 \pm 1.3 \mathrm{~mm}, \mathrm{M}: 11.7 \pm 1.4 \mathrm{~mm}\right)$. Maximum tetanic contractile force was not significantly different among groups and all groups were in the range of previously reported values for healthy EDL muscles $\left(19.8 \pm 8.1 \mathrm{~N} / \mathrm{m}^{2}\right.$; (Brooks and Faulkner 1988)). Muscle parallel $\left(E_{\mathrm{PE}}\right)$ and series $\left(\mathrm{E}_{\mathrm{SE}}\right)$ elasticity were unchanged for male and female mice on a HFD compared to CON (EPE: M p=0.62; F p=0.62; $E_{S E}: M p=0.86 ; F p=0.45$; Fig 4) and male mice given ASP or RSZ compared to M CON (EPE: ASP p=0.07; RSZ $p=0.07 ; E_{S E}: A S P p=0.07 ; R S Z p=0.70 ;$ Fig 4). However, female mice had significantly lower $E_{P E}$ and $E_{S E}$ when compared to males ( $p<0.05$ for both $E_{P E}$ and $E_{S E}$; Fig 4).

Overall, HFD treatment did not alter any of the muscle anatomical or functional properties measured. 
A

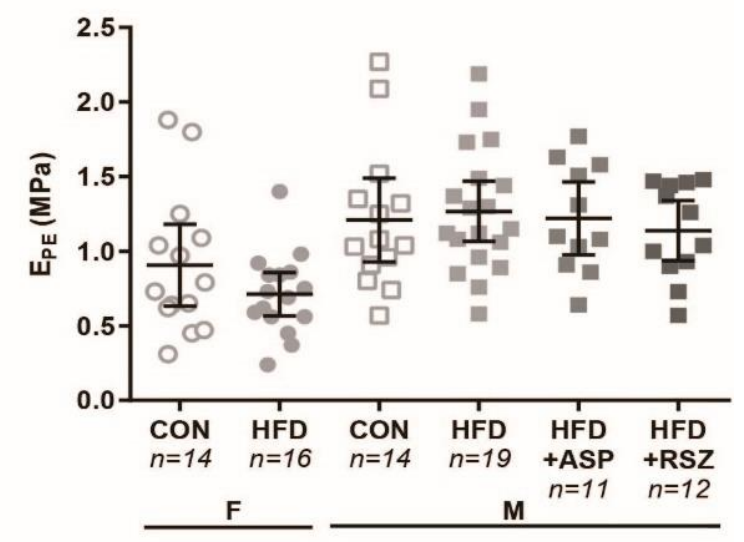

B

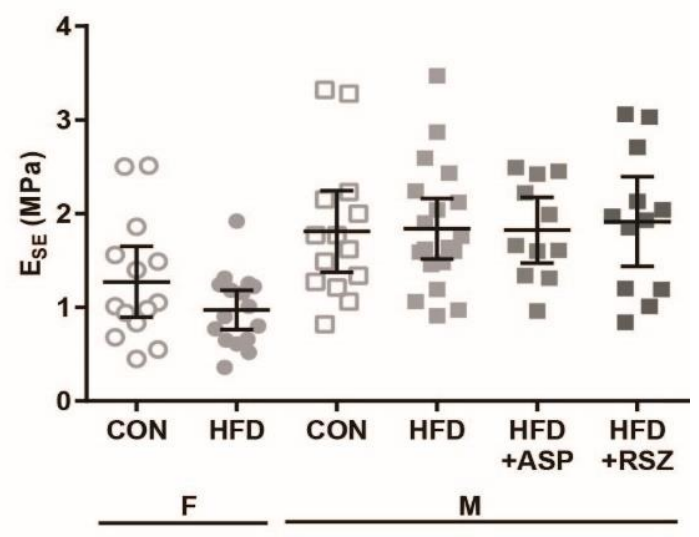

Figure 4: Muscle elasticity following high fat feeding no different than control. No difference was observed in muscle parallel $\left(E_{P E} ; A\right)$ and series $\left(E_{S E} ; \mathbf{B}\right)$ elasticity. Number of muscles used for both measurements shown on the $x$ axis of panel $\mathbf{A}$. Both elasticity measures were significantly lower than female mice when compared to males. Error bars denote \pm SEM; Groups compared by one-factor ANOVA with planned comparison contrasts followed by the Hochberg procedure for multiple comparison adjustment.

\section{DISCUSSION}

Balance instability and an increased rate of falling are seen in individuals with obesity of all ages and both sexes (Fjeldstad et al. 2008; Madigan et al. 2014; Menegoni et al. 2009). In this study we identified a possible contributing factor: impairment in muscle proprioceptor function. Muscle spindle afferent receptor endings were less responsive to 
both muscle stretch and sinusoidal vibration in adult mice fed a high fat diet for 10 wks. Both static (Fig 3 A-B) and dynamic muscle spindle afferent sensitivity (Fig 3 E-H) were decreased following diet induced obesity. This suggests that the central nervous system is receiving inaccurate muscle position and movement information during diet induced obesity.

Muscle spindle afferent function is critical to representing body position in space as well as fast error correction via the muscle stretch reflex (Proske and Gandevia 2012). We measured muscle spindle afferent function during passive conditions without gamma motor neuron tone or other central nervous system input. Our results suggest that muscle spindle input to alpha motor neurons is lower during obesity, potentially decreasing muscle tone. Similarly, our results suggest that muscle stretch reflex strength would be lower in obese animals unless obesity also leads to increased gamma motor neuron tone and/or central reflex excitability. Future studies are necessary to determine the effect on muscle tone and motor behavior from these observed changes in passive mechanoreception. Alterations in muscle spindle afferent function occur in two other conditions associated with impaired balance: aging (Kim et al. 2007; Miwa et al. 1995; Swash and Fox 1972) and diabetes (Muller et al. 2008; van Deursen et al. 1998). In particular, aged rats exhibit decreased firing rates during static stretch and decreased dynamic sensitivity (Miwa et al. 1995), similar to what we have observed. Due to the important role of muscle spindle afferent sensory input to the maintenance of balance, the deficits we observe could contribute to motor instability during obesity.

While the same general pattern of decreased muscle spindle afferent sensitivity in obesity was observed in both sexes, the effect was not as strong in the females for dynamic sensitivity (Fig 3 E\&F) and baseline firing changes. This could be due to the 
fact that female mice on HFD were not as heavy as the males (Fig 2) and/or the fact that the metabolic and inflammatory responses to diet induced obesity are reduced in female mice (Pettersson et al. 2012; Stubbins et al. 2012). However, there was also a sex difference in muscle spindle afferent function in control conditions. To our knowledge this is the first study to directly compare male and female muscle spindle afferent responses, although mixed sex groups have been used in previous studies. Afferents from female mice had lower firing rates at all points during stretch (Fig $3 A \& B$ ), were more likely to have lower or no firing at $L_{o}$, and were less likely to entrain to vibration (Fig 3 E\&G). Similarly, baseline, peak, and plateau tension normalized to CSA and both parallel and series muscle elasticity were lower in female mice (Fig $4 \mathrm{~A} \& \mathrm{~B}$ ), which is consistent with the lower afferent firing rates observed. Whether these sex differences in passive signaling properties occur in the whole animal or if they are compensated for with increased gamma motor neuron drive or other central nervous system mechanisms is unknown and should be addressed in future studies.

Changes to muscle spindle afferent signaling could be due to changes in neural mechanosensation or changes in muscle mechanical properties. We did not observe any changes in muscle weight, CSA, $\mathrm{L}_{\circ}$, or maximal tetanic contractile force, similar to previous findings (DeNies et al. 2014; Shortreed et al. 2009). Both parallel and series muscle elasticity were also unchanged with diet induced obesity (Fig 4 A\&B). In short, we found no evidence of any muscle changes that could alter the mechanical forces seen by the muscle spindle afferents. However, the intrafusal fiber type(s) that muscle spindle afferents contact are critical for determining their sensitivity to muscle stretch and movement (Matthews 1981) and our measurements were not made on intrafusal fibers directly. Changes in the number and fiber composition of intrafusal fibers have been 
observed in other conditions, including aging (Kararizou et al. 2005; Liu et al. 2005). Future studies are needed to determine if spindle intrafusal fiber properties are altered with diet induced obesity.

In addition to weight gain, diet induced obesity is accompanied by metabolic changes, a chronic inflammatory state (Gregor and Hotamisligil 2011), and increased sympathetic nervous system activation (Davy and Orr 2009) and these factors could mediate the changes to muscle spindle afferent properties that we have observed. For instance, inflammatory factors enhance the response of nociceptive afferents to stimuli (Opree and Kress 2000) and potentially alter muscle spindle afferent response properties as well since the activity of both ion channels shown to be involved in spindle afferent mechanotransduction, Piezo2 (Woo et al. 2015) and ASIC3 (Lin et al. 2016), can be modulated by inflammatory factors (Dubin et al. 2012; Jones et al. 2005; Li et al. 2010). Fourteen weeks on this diet causes male, but not female mice, to exhibit the early stages of metabolic syndrome, including hyperinsulinemia, higher blood glucose, and insulin tolerance (Pettersson et al. 2012). Type II Diabetes is not observed and we think it is unlikely that peripheral neuropathy occurs following 10 weeks on a HFD. We tested the hypothesis that targeting non-weight related aspects of obesity, including inflammation, could improve spindle afferent function. ASP, a non-steroidal antiinflammatory drug which also improves glucose tolerance (Kendig et al. 2008), did not improve static or dynamic spindle afferent sensitivity (Fig 3 C-D, J) even though ASP treated animals were not significantly heavier than controls on average (Fig 2).

The diabetes drug RSZ reduces inflammation and normalizes insulin sensitivity, among other actions (Berger and Moller 2002). Afferents from RSZ treated animals still exhibited significant weight gain (Fig 2) and impaired static sensitivity (Fig 3 C-D), but 
had similar dynamic sensitivity as controls (Fig $3 \mathrm{I})$. A limitation of this study was that we only used one dose which may have varied based on individual animal consumption rates. Future studies could determine if more effectively targeting one or more of RSZ's sites of action can completely rescue muscle spindle afferent sensitivity in the presence of weight gain.

In summary, we have shown changes in peripheral mechanosensation by muscle spindle afferents following diet induced obesity in adult mice. Due to the importance of muscle spindle afferent input to proprioception, future studies should investigate whether similar alterations occur in humans and contribute to the impaired balance and increased risk of falling seen in populations with obesity. 


\section{CHAPTER 3}

\section{CONCLUSIONS AND FUTURE DIRECTIONS}

In our study, we found that muscle spindle afferent function was decreased in both male and female mice following high fat diet induced obesity. This suggests that sensory information from the muscle spindle afferents to the alpha motor neurons is diminished during obesity, possibly leading to decreased muscle tone. The stretch reflex activated as a result of muscle spindle afferent activation due to stretch is also important for maintaining muscle tone (Cameron-Tucker, 1983). Hence, our results also suggest that obesity may lead to decreased stretch reflex strength unless the diminished input to alpha motor neurons is compensated by some central mechanism. Future studies can test whether obesity impacts stretch reflex strength and excitability.

Changes in muscle spindle afferent function have been reported in other pathological conditions, such as aging (Miwa et al. 1995; Kim et al. 2007; Rosant et al. 2007; Shaffer and Harrison 2007) and diabetes (Nardone and Schieppati 2004; Muller et al. 2008a). Similar to our results, both dynamic and static response of spindle afferents to ramp and hold stretch are reduced in aged rats (Miwa et al. 1995). The change in muscle spindle afferent sensitivity due to aging has been linked to factors such as an increase in passive stiffness (Rosant and Pérot 2006) as a result of increased capsular collagen (Miwa et al. 1995). Additionally, with increasing age, the mean number of intrafusal muscle fibers in the muscle decreases (Swash and Fox 1972). Alterations of mechanical and ionic properties in the intrafusal fibers could also contribute to reduced dynamic firing of the primary afferents (Kim et al. 2007). Morphological changes of spindle afferent endings could also contribute to reduced dynamic and static sensitivity. The primary endings of sensory afferents in aged rats have fewer or no annulospiral endings.(Kim et al. 2007). 
Diabetic mice with abnormal innervations of Group la spindle afferents have impaired balance and gait during a beam walk apparatus test (Muller et al. 2008b). In our study, we did not directly record from the intrafusal fibers. Mechanical changes in the muscle itself could also impact muscle spindle afferent function. However, similar to previous reports, we did not find any differences in muscle weight, CSA, $\mathrm{L}_{0}$, or maximal tetanic contractile force in the obese mice compared to controls (DeNies et al. 2014; Shortreed et al. 2009). Additionally, high fat diet induced obesity did not alter either parallel or series muscle elasticity (Fig 4 A\&B). In summary, we have no evidence that muscle mechanical forces have changed with obesity. Future studies should explore how obesity alters intrafusal muscle fibers and whether there are any morphological changes in muscle spindle afferents following high fat diet induced obesity.

We found that in both male and female obese mice muscle spindle afferent response to stretch was decreased; however, in female mice the effect on dynamic stretch response was not as large (Fig 3A). Also, unlike obese male mice, there was not much difference in baseline firing between female obese mice and control. One possible explanation for this could be that female mice in our study did not gain as much weight as male obese mice (Fig 2). There is considerable evidence for sex differences in skeletal muscle properties such as muscle mass and strength (Doherty 2001), fiber type composition ((Denies et al. 2014), insulin sensitivity, and lipid metabolism (Hoeg et al. 2011). Metabolic changes associated with obesity are less severe in female mice fed a high fat diet (Pettersson et al. 2012) and ovarian hormones in female mice have been suggested to play a protective role in preventing high fat diet induced weight gain (Hong et al. 2009) and low grade systemic inflammation due to obesity (Pettersson et al. 2012). Whether differences in skeletal muscle composition and metabolic regulatory pathways influence the stretch 
sensitivity of muscle spindle afferents is not known and should be investigated in future studies.

There is considerable evidence suggesting that obesity is linked to chronic low grade systemic inflammation (Dandona, Aljada, Chaudhuri, Mohanty, \& Garg, 2005; Gregor \& Hotamisligil, 2011) and enhanced sympathetic nervous activity (Troisi et al. 1991; Hall et al. 2010). An increase in the secretion of proinflammatory cytokine TNF- $\alpha$ from adipose tissue has been observed in obese mice (Tzanavari et al. 2010). TNF- $\alpha$ has also been shown to increase excitability of sensory neurons in the dorsal root ganglion (Liu et al. 2002). Piezo2 has recently been identified as one of the principal mechanotransduction ion channels on proprioceptive sensory afferents (Woo et al. 2015). At least one inflammatory factor, bradykinin, enhances the activity of the piezo2 mechnotransductive ion channels present on sensory afferents (Dubin et al. 2012). This suggests that inflammatory cytokines released by adipose tissue may also modulate muscle spindle afferent response to stretch.

In our study, we also tested whether targeting factors other than weight gain, such as inflammation, could reverse impaired muscle spindle afferent function. We tested two drugs: rosiglitazone and aspirin. Rosiglitazone is a peroxisome proliferator-activated gamma agonist and has multiple target actions such as improving insulin resistance (Sundaresan et al. 2016) and decreasing sympathetic nervous system activity (Yosefy et al. 2004) and inflammation (Pini et al. 2012). Aspirin is a cyclooxygenase inhibitor and improves glucose metabolism (Hundal et al. 2002) and lowers inflammation (van Diepen et al. 2011). In our study, neither aspirin nor rosiglitazone could completely rescue the muscle spindle afferent signaling deficits in male mice, although rosiglitazone could improve dynamic but not static muscle spindle afferent sensitivity (Fig 3, C-D, J). A 
limitation of this study is that we only tried a single dose of drug. In the future, we would like to conduct a dose response study with the drug rosiglitazone to see if we could fully rescue muscle spindle afferent impairments seen in the mouse model of diet induced obesity. Further, we could also target pathways affected by rosiglitazone, such as the TNF- $\alpha$ pathway or sympathetic nervous system signaling, to elucidate the molecular mechanism by which obesity alters muscle spindle afferent response.

Proprioceptive input from the afferents innervating the muscle spindle are important for maintaining balance. In our study, we have shown that following high fat diet induced obesity, muscle spindle afferent function is impaired in adult mice. Future studies should test whether this is true for the human population. Further studies should also elucidate the exact mechanism by which obesity causes this alteration in peripheral mechanosensation of muscle spindle afferents. 


\section{LITERATURE CITED}

Berger J, and Moller DE. The mechanisms of action of PPARs. Annu Rev Med 53: 409435, 2002.

Billot M, Handrigan GA, Simoneau M, Corbeil P, and Teasdale N. Short term alteration of balance control after a reduction of plantar mechanoreceptor sensation through cooling. Neurosci Lett 535: 40-44, 2013.

Brooks SV, and Faulkner JA. Contractile properties of skeletal muscles from young, adult and aged mice. J Physiol 404: 71-82, 1988.

CAMERON-TUCKER $\mathrm{H}$. The Neurophysiology of Tone: The Role of the Muscle Spindle and the Stretch Reflex. Aust J Physiother 29: 155-165, 1983.

Cheung PP, and Azevedo LB. Sensory integration and response to balance perturbation in overweight physically active individuals. J Mot Behav 47: 436-441, 2015.

Colné P, Frelut ML, Pérès G, Thoumie P. Postural control in obese adolescents assessed by limits of stability and gait initiation. Gait Posture 28: 164-169, 2008.

Corbeil P, Simoneau M, Rancourt D, Tremblay A, and Teasdale N. Increased risk for falling associated with obesity: mathematical modeling of postural control. Neural Systems and Rehabilitation Engineering, IEEE Transactions on 9: 126-136, 2001.

Costello KE, Matrangola SL, and Madigan ML. Independent effects of adding weight and inertia on balance during quiet standing. BioMed Eng Online 11: 20, 2012.

da Rocha ES, Bratz DTK, Gubert LC, de David A, and Carpes FP. Obese children experience higher plantar pressure and lower foot sensitivity than non-obese. Clinical Biomechanics 29: 822-827, 2014.

Dandona P, Aljada A, Chaudhuri A, Mohanty P, Garg R. Metabolic syndrome: A comprehensive perspective based on interactions between obesity, diabetes, and inflammation. Circulation 111: 1448-1454, 2005.

Davy KP, and Orr JS. Sympathetic nervous system behavior in human obesity. Neuroscience and biobehavioral reviews 33: 116-124, 2009.

Denies MS, Johnson J, Maliphol AB, Bruno M, Kim A, Rizvi A, Rustici K, Medler S. Dietinduced obesity alters skeletal muscle fiber types of male but not female mice. Physiol Rep 2: e00204, 2014.

D'Hondt E, Deforche B, De Bourdeaudhuij I, and Lenoir M. Childhood obesity affects fine motor skill performance under different postural constraints. Neurosci Lett 440: 72-75, 2008. 
D'Hondt E, Deforche B, De Bourdeaudhuij I, Gentier I, Tanghe A, Shultz S, and Lenoir M. Postural balance under normal and altered sensory conditions in normal-weight and overweight children. Clin Biomech (Bristol, Avon) 26: 84-89, 2011.

Doherty TJ. The influence of aging and sex on skeletal muscle mass and strength. [Online]. Curr Opin Clin Nutr Metab Care 4: 503-8, 2001.

http://www.ncbi.nlm.nih.gov/pubmed/11706284 [11 Mar. 2017].

Dubin AE, Schmidt M, Mathur J, Petrus MJ, Xiao B, Coste B, Patapoutian A.

Inflammatory Signals Enhance Piezo2-Mediated Mechanosensitive Currents. Cell Rep 2: 511-517, 2012.

Dutil M, Handrigan G a., Corbeil P, Cantin V, Simoneau M, Teasdale N, Hue O. The impact of obesity on balance control in community-dwelling older women. Age (Omaha). (2012). doi: 10.1007/s11357-012-9386-x.

van Diepen J a., Vroegrijk IOCM, Berbee JFP, Shoelson SE, Romijn J a., Havekes LM, Rensen PCN, Voshol PJ. Aspirin reduces hypertriglyceridemia by lowering VLDLtriglyceride production in mice fed a high-fat diet. AJP Endocrinol Metab 301: E1099E1107, 2011.

Finkelstein EA, Chen H, Prabhu M, Trogdon JG, and Corso PS. The relationship between obesity and injuries among U.S. adults. Am J Health Promot 21: 460-468, 2007.

Fjeldstad C, Fjeldstad A, Acree L, Nickel K, and Gardner A. The influence of obesity on falls and quality of life. Dynamic Medicine 7: 4, 2008.

Flegal KM, Carroll MD, Kit BK, Ogden CL. Prevalence of Obesity and Trends in the Distribution of Body Mass Index Among US Adults, 1999-2010. JAMA 307: 491, 2012.

Franco JA, Kloefkorn HE, Hochman S, and Wilkinson KA. An in vitro adult mouse muscle-nerve preparation for studying the firing properties of muscle afferents. Journal of visualized experiments : JoVE 51948, 2014.

Fritz-Ritson D. The anatomy and physiology of the muscle spindle, and its role. J Can Chiropr Ass 26: 144-150, 1982.

Ganz DA, Bao Y, Shekelle PG, and Rubenstein LZ. Will my patient fall? Jama 297: 7786, 2007.

Gardner RM, Salaz V, Reyes B, and Brake SJ. Sensitivity to proprioceptive feedback in obese subjects. Perceptual and motor skills 57: 1111-1118, 1983.

Gentier I, D'Hondt E, Shultz S, Deforche B, Augustijn M, Hoorne S, Verlaecke K, De Bourdeaudhuij I, Lenoir M. Fine and gross motor skills differ between healthy-weight and obese children. Res Dev Disabil 34: 4043-4051, 2013. 
Gregor MF, and Hotamisligil GS. Inflammatory Mechanisms in Obesity. Annual Review of Immunology 29: 415-445, 2011.

Griffin TM, Fermor B, Huebner JL, Kraus VB, Rodriguiz RM, Wetsel WC, Cao L, Setton LA, and Guilak F. Diet-induced obesity differentially regulates behavioral, biomechanical, and molecular risk factors for osteoarthritis in mice. Arthritis research \& therapy 12: R130, 2010.

Guskiewicz KM, Perrin DH. Research and Clinical Applications of Assessing Balance. J Sport Rehabil : 45-63, 1996.

Hall JE, da Silva AA, do Carmo JM, Dubinion J, Hamza S, Munusamy S, Smith G, Stec DE. Obesity-induced hypertension: role of sympathetic nervous system, leptin, and melanocortins. J Biol Chem 285: 17271-6, 2010.

Handrigan GA, Berrigan F, Hue O, Simoneau M, Corbeil P, Tremblay A, and Teasdale $\mathrm{N}$. The effects of muscle strength on center of pressure-based measures of postural sway in obese and heavy athletic individuals. Gait Posture 35: 88-91, 2012.

Himes CL, and Reynolds SL. Effect of obesity on falls, injury, and disability. J Am Geriatr Soc 60: 124-129, 2012.

Hoeg LD, Sjoberg KA, Jeppesen J, Jensen TE, Frosig C, Birk JB, Bisiani B, Hiscock N, Pilegaard H, Wojtaszewski JFP, Richter EA, Kiens B. Lipid-Induced Insulin Resistance Affects Women Less Than Men and Is Not Accompanied by Inflammation or Impaired Proximal Insulin Signaling. Diabetes 60: 64-73, 2011.

Hong J, Stubbins RE, Smith RR, Harvey AE, and Nunez NP. Differential susceptibility to obesity between male, female and ovariectomized female mice. Nutrition journal 8: 11, 2009.

Hue O, Simoneau M, Marcotte J, Berrigan F, Dore J, Marceau P, Marceau S, Tremblay A, and Teasdale N. Body weight is a strong predictor of postural stability. Gait Posture 26: 32-38, 2007.

Hundal RS, Petersen KF, Mayerson AB, Randhawa PS, Inzucchi S, Shoelson SE, Shulman Gl. Mechanism by which high-dose aspirin improves glucose metabolism in type 2 diabetes. J Clin Invest 109: 1321-1326, 2002.

Hunt CC, and Kuffler SW. Stretch receptor discharges during muscle contraction. $J$ Physiol 113: 298-315, 1951.

Jones RCW, Xu L, and Gebhart GF. The Mechanosensitivity of Mouse Colon Afferent Fibers and Their Sensitization by Inflammatory Mediators Require Transient Receptor Potential Vanilloid 1 and Acid-Sensing Ion Channel 3. The Journal of Neuroscience 25: 10981-10989, 2005. 
Kararizou E, Manta P, Kalfakis N, and Vassilopoulos D. Morphometric study of the human muscle spindle. Analytical and quantitative cytology and histology/the

International Academy of Cytology [and] American Society of Cytology 27: 1-4, 2005.

Kendig EL, Schneider SN, Clegg DJ, Genter MB, and Shertzer HG. Over-the-counter analgesics normalize blood glucose and body composition in mice fed a high fat diet. Biochemical pharmacology 76: 216-224, 2008.

Kim GH, Suzuki S, and Kanda K. Age-related physiological and morphological changes of muscle spindles in rats. $J$ Physiol 582: 525-538, 2007.

Ko S, Stenholm S, and Ferrucci L. Characteristic gait patterns in older adults with obesity--results from the Baltimore Longitudinal Study of Aging. J Biomech 43: 11041110, 2010.

Koltzenburg M, Stucky CL, and Lewin GR. Receptive properties of mouse sensory neurons innervating hairy skin. J Neurophysiol 78: 1841-1850, 1997.

Li W-G, Yu Y, Zhang Z-D, Cao H, and Xu T-L. ASIC3 Channels Integrate Agmatine and Multiple Inflammatory Signals through the Nonproton Ligand Sensing Domain. Molecular Pain 6: 1-12, 2010.

Lin SH, Cheng YR, Banks RW, Min MY, Bewick GS, and Chen CC. Evidence for the involvement of ASIC3 in sensory mechanotransduction in proprioceptors. Nature communications 7: 11460, 2016.

Liu B, Li H, Brull SJ, Zhang J-M. Increased sensitivity of sensory neurons to tumor necrosis factor alpha in rats with chronic compression of the lumbar ganglia. [Online]. $J$ Neurophysiol 88: 1393-9, 2002.

Liu J-X, Eriksson P-O, Thornell L-E, and Pedrosa-Domellöf F. Fiber content and myosin heavy chain composition of muscle spindles in aged human biceps brachii. Journal of Histochemistry \& Cytochemistry 53: 445-454, 2005.

Madigan M, Rosenblatt NJ, and Grabiner MD. Obesity as a Factor Contributing to Falls by Older Adults. Curr Obes Rep 3: 348-354, 2014.

Matrangola SL, Madigan ML. The effects of obesity on balance recovery using an ankle strategy. Hum Mov Sci 30: 584-595, 2011.

Matter KC, Sinclair SA, Hostetler SG, and Xiang H. A Comparison of the Characteristics of Injuries Between Obese and Non-obese Inpatients. Obesity 15: 2384-2390, 2007.

Matthews PBC editor. Muscle spindles: their messages and their fusimotor supply. Bethesda, MD: American Physiological Society, 1981, p. 189-228. 
McGraw B, McClenaghan BA, Williams HG, Dickerson J, and Ward DS. Gait and postural stability in obese and nonobese prepubertal boys. Arch Phys Med Rehabil 81: 484-489, 2000.

Menegoni F, Galli M, Tacchini E, Vismara L, Cavigioli M, and Capodaglio P. Genderspecific effect of obesity on balance. Obesity 17: 1951-1956, 2009.

Mignardot J-B, Olivier I, Promayon E, and Nougier V. Obesity impact on the attentional cost for controlling posture. PLoS One 5: e14387, 2010.

Mitchell RJ, Lord SR, Harvey L a., Close JCT. Associations between obesity and overweight and fall risk, health status and quality of life in older people. Aust $N Z J$ Public Health 38: 13-18, 2014.

Miwa T, Miwa Y, and Kanda K. Dynamic and static sensitivities of muscle spindle primary endings in aged rats to ramp stretch. Neurosci Lett 201: 179-182, 1995.

Muller KA, Ryals JM, Feldman EL, and Wright DE. Abnormal muscle spindle innervation and large-fiber neuropathy in diabetic mice. Diabetes 57: 1693-1701, 2008.

Nardone A, Schieppati M. Group II spindle fibres and afferent control of stance. Clues from diabetic neuropathy. Clin Neurophysiol 115: 779-89, 2004.

Opree A, and Kress M. Involvement of the proinflammatory cytokines tumor necrosis factor-alpha, IL-1 beta, and IL-6 but not IL-8 in the development of heat hyperalgesia: effects on heat-evoked calcitonin gene-related peptide release from rat skin. $J$ Neurosci 20: 6289-6293, 2000.

Perry SD, Mcllroy WE, Maki BE. The role of plantar cutaneous mechanoreceptors in the control of compensatory stepping reactions evoked by unpredictable, multi-directional perturbation. 2000.

Pettersson US, Walden TB, Carlsson PO, Jansson L, and Phillipson M. Female mice are protected against high-fat diet induced metabolic syndrome and increase the regulatory T cell population in adipose tissue. PLoS One 7: e46057, 2012.

Pini M, Rhodes DH, Castellanos KJ, Cabay RJ, Grady EF, Fantuzzi G. Rosiglitazone improves survival and hastens recovery from pancreatic inflammation in obese mice. PLoS One 7, 2012.

Proske U, and Gandevia SC. The Proprioceptive Senses: Their Roles in Signaling Body Shape, Body Position and Movement, and Muscle Force. Physiol Rev 92: 1651-1697, 2012.

Rodriguez-Miguelez P, Fernandez-Gonzalo R, Almar M, Mejías Y, Rivas A, de Paz JA, Cuevas MJ, González-Gallego J. Role of Toll-like receptor 2 and 4 signaling pathways on the inflammatory response to resistance training in elderly subjects. Age (Omaha) 36: 9734, 2014. 
Rosant $C$, Nagel M-D, Pérot C. Aging affects passive stiffness and spindle function of the rat soleus muscle. Exp Gerontol 42: 301-8, 2007.

Rosant C, Pérot C. An index of spindle efficacy obtained by measuring electroneurographic activity and passive tension in the rat soleus muscle. J Neurosci Methods 150: 272-8, 2006.

Shaffer SW, Harrison AL. Aging of the Somatosensory System: A Translational Perspective. Phys Ther 87: 193-207, 2007.

Shortreed KE, Krause MP, Huang JH, Dhanani D, Moradi J, Ceddia RB, and Hawke TJ. Muscle-specific adaptations, impaired oxidative capacity and maintenance of contractile function characterize diet-induced obese mouse skeletal muscle. PLoS One 4: e7293, 2009.

Simoneau M, and Teasdale N. Balance control impairment in obese individuals is caused by larger balance motor commands variability. Gait Posture 41: 203-208, 2015.

Singh D, Park W, Levy MS, Jung ES. The effects of obesity and standing time on postural sway during prolonged quiet standing. Ergonomics 52: 977-986, 2009

Stubbins RE, Holcomb VB, Hong J, and Núñez NP. Estrogen modulates abdominal adiposity and protects female mice from obesity and impaired glucose tolerance. European journal of nutrition 51: 861-870, 2012.

Sundaresan A, Radhiga T, Pugalendi KV. Ursolic acid and rosiglitazone combination improves insulin sensitivity by increasing the skeletal muscle insulin-stimulated IRS-1 tyrosine phosphorylation in high-fat diet-fed C57BL/6J mice. J Physiol Biochem 72: 345352, 2016.

Swash M, and Fox KP. The effect of age on human skeletal muscle studies of the morphology and innervation of muscle spindles. J Neurol Sci 16: 417-432, 1972.

Teasdale N, Simoneau M, Corbeil P, Handrigan G, Tremblay A, Hue O. Obesity Alters Balance and Movement Control. Curr Obes Rep 2: 235-240, 2013.

Tiikkainen M, Häkkinen A-M, Korsheninnikova E, Nyman T, Mäkimattila S, Yki-Järvinen $\mathrm{H}$. Effects of Rosiglitazone and Metformin on Liver Fat Content, Hepatic Insulin Resistance, Insulin Clearance, and Gene Expression in Adipose Tissue in Patients With Type 2 Diabetes. Diabetes 53, 2004.

Troisi RJ, Weiss ST, Parker DR, Sparrow D, Young JB, Landsberg L. Relation of obesity and diet to sympathetic nervous system activity. Hypertens (Dallas, Tex 1979) 17: 669$77,1991$.

Tzanavari T, Giannogonas P, Karalis KP. TNF-\&amp;alpha; and Obesity. In: TNF Pathophysiology. KARGER, p. 145-156. 
van Deursen MRW, Sanchez MM, Ulbrecht SJ, and Cavanagh RP. The role of muscle spindles in ankle movement perception in human subjects with diabetic neuropathy. Experimental Brain Research 120: 1-8, 1998.

Wang L, Li JX, Xu DQ, Hong YL. Proprioception of ankle and knee joints in obese boys and nonobese boys. [Online]. Med Sci Monit 14: CR129-35, 2008.

http://www.ncbi.nlm.nih.gov/pubmed/18301356 [7 Mar. 2017].

Watanabe I, Okubo J. THE ROLE OF THE PLANTAR MECHANORECEPTOR IN EQUILIBRIUM CONTROL. Ann N Y Acad Sci 374: 855-864, 1981.

Wilkinson KA, Kloefkorn HE, and Hochman S. Characterization of muscle spindle afferents in the adult mouse using an in vitro muscle-nerve preparation. PLoS One 7: e39140, 2012.

Wolff AV, Niday AK, Voelker KA, Call JA, Evans NP, Granata KP, and Grange RW. Passive mechanical properties of maturing extensor digitorum longus are not affected by lack of dystrophin. Muscle Nerve 34: 304-312, 2006.

Woo S-H, Lukacs V, de Nooij JC, Zaytseva D, Criddle CR, Francisco A, Jessell TM, Wilkinson KA, and Patapoutian A. Piezo2 is the principal mechanotransduction channel for proprioception. Nat Neurosci 18: 1756-1762, 2015.

Wu X, and Madigan ML. Impaired plantar sensitivity among the obese is associated with increased postural sway. Neurosci Lett 583C: 49-54, 2014.

Yadav RL, Sharma D, Yadav PK, Shah DK, Agrawal K, Khadka R, Islam MN. Somatic neural alterations in non-diabetic obesity: a cross-sectional study. BMC Obes 3: 50, 2016.

Yang Y, Smith DL, Keating KD, Allison DB, and Nagy TR. Variations in body weight, food intake and body composition after long-term high-fat diet feeding in C57BL/6J mice. Obesity 22: 2147-2155, 2014.

Yosefy C, Magen E, Kiselevich A, Priluk R, London D, Volchek L, Viskoper RJ. Rosiglitazone improves, while Glibenclamide worsens blood pressure control in treated hypertensive diabetic and dyslipidemic subjects via modulation of insulin resistance and sympathetic activity. [Online]. J Cardiovasc Pharmacol 44: 215-22, 2004. 